\title{
The Manufacture of Bleached Kraft Pulp from Persimmon Byproducts
}

\author{
Hae Min Jo, ${ }^{a}$ Ji Young Lee, ${ }^{b} *$ Su Ho Kim, ${ }^{a}$ and Kyung Min Kim ${ }^{a}$ \\ The authors explored the possibility of using persimmon byproducts as \\ raw materials for obtaining kraft pulps. Various unbleached and bleached \\ kraft pulps via pulping and bleaching processes were prepared. Then, their \\ characteristics were determined and compared with those of commercial \\ kraft pulps. For the highest screened yield of persimmon byproduct \\ unbleached kraft pulps, the optimal pulping conditions were a liquid ratio \\ of $5: 1$, an active alkali concentration of $25 \%$, a sulfidity of $30 \%$, and a \\ cooking time of $3 \mathrm{~h}$. Furthermore, the authors obtained persimmon \\ byproduct bleached kraft pulps (PB-BKPs) with an ISO brightness of $73 \%$ \\ via three-stage bleaching using $3 \% \mathrm{ClO}_{2}, 1.5 \% \mathrm{NaOH}$, and $3.5 \% \mathrm{ClO}_{2}$. \\ Moreover, PB-BKP prepared under optimal pulping and bleaching \\ conditions had physical characteristics similar to those of commercial \\ mixed-hardwood bleached kraft pulp, but with relatively low ISO brightness. \\ Therefore, as raw materials, persimmon byproducts can be used for \\ manufacturing a bleached kraft pulp.
}

Keywords: Agricultural byproduct; Persimmon byproduct; Kraft pulp; Yield; Pulping; Bleaching

Contact information: a: Department of Forest Products; $b$ : Department of Environmental Materials Science/IALS, Gyeongsang National University, Jinju 52828, Republic of Korea;

*Corresponding author: paperyjy@gnu.ac.kr

\section{INTRODUCTION}

The Korean paper industry has been steadily growing with the development of various paper products and production technologies. However, it is essential to overcome limitations, such as the low pulp self-sufficiency rate of $20 \%$ and the shortage of fibrous natural and fossil fuel resources (Eom 2014; Jeong 2016) for the continued growth of the Korean paper industry. Generally, agricultural byproducts are obtained from agricultural produce. According to a report published by the Ministry of Agriculture, Food and Rural Affairs in the Republic of Korea (Kim et al. 2014), 8,909 thousand tons of agricultural byproducts were theoretically generated in 2013 . The most common were rice byproducts $(65 \%)$, such as rice husk and rice straw, followed by fruit byproducts (18\%) and field byproducts (16\%). Most agricultural byproducts are fibrous resources that have been evaluated for use in energy and materials industries (Fahmy et al. 2017; Jesus et al. 2017; Fillat et al. 2018; Wi et al. 2018; Iriondo-DeHond et al. 2019). However, the actual amount of such byproducts in various industries is low (El-Sakhawy et al. 1996; Bhardwaj et al. 2005). In particular, because of the lack of natural resources in the Republic of Korea, technological development for recycling agricultural byproducts that are currently being discarded is necessary.

Persimmon is one of the highest produced fruits in the Republic of Korea and forms a large proportion of the fruit market. In 2017, approximately 300,000 tons of persimmon were produced from an area of larger than 24,000 ha (Kang 2017). While cultivating persimmon, many byproducts are generated via pruning; however, these are crushed and used as compost or subsequently discarded. The use of persimmon 
byproducts in pulp and paper mills can positively affect the domestic environment and the Korean pulp and paper industry, which lacks natural fibrous resources.

Previously, studies have reported that many types of agricultural byproducts have chemical and physical characteristics that are suitable for producing kraft pulp (Lee et al. 2014; Kaur et al. 2017). Because persimmon byproducts are fibrous resources, they are expected to be used in both the pulp and paper industry. However, few studies have examined the pulping or papermaking technology of agricultural byproducts.

In the present study, the authors evaluated the possibility of using persimmon byproducts as raw materials for manufacturing bleached kraft pulp. Then the chemical composition of the persimmon byproducts was analyzed, several kraft pulping processes to prepare persimmon byproduct unbleached kraft pulps (PB-UKPs) under various pulping conditions were performed, and their pulp yields were measured. After preparing the $\mathrm{PB}-\mathrm{UKP}$, the authors performed three-stage bleaching to prepare the persimmon byproduct bleached kraft pulp (PB-BKP). Both PB-UKP and PB-BKP were characterized, and their characteristics were compared with those of commercial bleached kraft pulps (BKPs).

\section{EXPERIMENTAL}

\section{Materials}

After pruning, the persimmon byproducts from Dangam Farm, Micheon-myeon, Jinju-si, Gyeongsangnam-do (Republic of Korea) were collected. As a control, softwood bleached kraft pulp (SwBKP) obtained from pine and mixed-hardwood bleached kraft pulp (HwBKP) was used and supplied by Moorim Paper (Jinju, Republic of Korea). Various chemicals for chemical composition analysis, kraft pulping, and bleaching were used.

\section{Methods}

Preparation of persimmon byproduct and analysis of chemical composition

Some severely rotten portions of persimmon byproducts were removed and allowed to air dry for $24 \mathrm{~h}$. As shown in Fig. 1, before the experiments, persimmon byproduct chips of approximately 0.5 to $1.5 \mathrm{~cm}$ thickness were prepared.
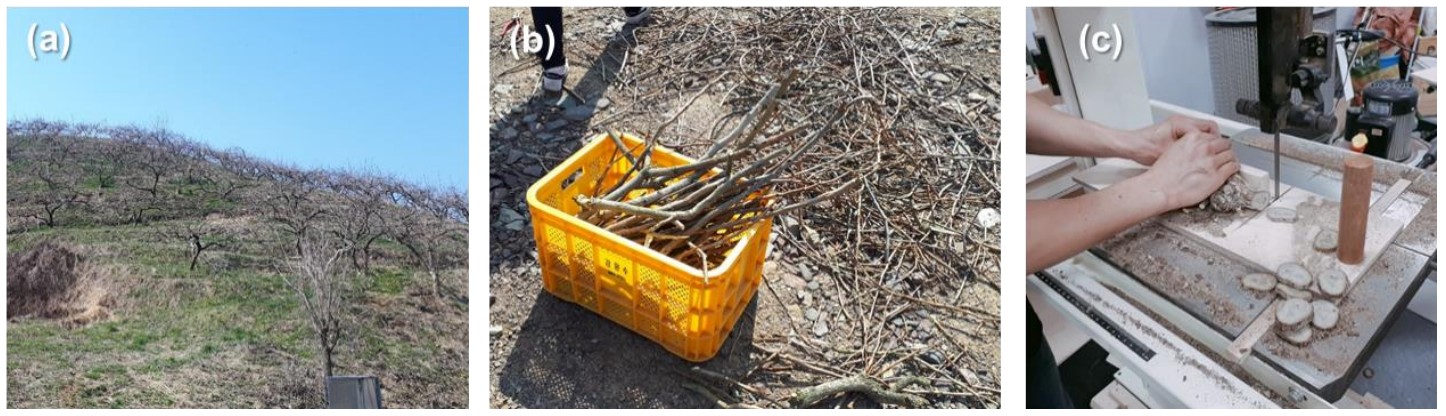

Fig. 1. (a) persimmon farm, (b) the persimmon byproducts, and (c) preparation of persimmon byproduct chips for chemical composition analysis and kraft pulping

The chips were then fractionated using a vibratory sieve shaker (J-VSS; JISICO Scientific Instruments, Seoul, Republic of Korea) and equipped with a 60-mesh sieve to remove foreign substances. After fractionation, the chips remaining on the 60 -mesh sieve were used for subsequent experiments. 
The authors analyzed the chemical composition of the persimmon byproducts as follows and measured the extractive content and ash content according to the following standards: KS M 7035 (2018) and TAPPI T211 om-07 (2007). The lignin content was analyzed using the chlorite method (Wise et al. 1946), and holocellulose was determined by weighing the delignified specimens, whereas alpha-cellulose was quantified by dissolving hemicellulose from delignified specimens using $17.5 \% \mathrm{NaOH}$. To compare the chemical composition of persimmon byproducts with those of various fibrous resources, the authors conducted a reference search.

\section{Kraft pulping and yield measurement of $P B-U K P$}

A laboratory digester (Daeil Machinery Co., Ltd., Daejeon, Republic of Korea) was used. The persimmon byproduct and white liquor were added and stirred for 20 min at room temperature (approximately $20{ }^{\circ} \mathrm{C}$ ) without heating. The cooking temperature was then set to $170{ }^{\circ} \mathrm{C}$, and the cooking time was selected according to the conditions: it took 25 min of cooking time to reach $170{ }^{\circ} \mathrm{C}$ from room temperature.

As shown in Table 1, to make kraft pulps from persimmon byproduct chips, the pulping conditions were set by adjusting the liquor-to-wood ratio, active alkali (AA), and cooking time. Under all conditions, the sulfidity was fixed to $30 \%$.

Table 1. Pulping Conditions for Making PB-UKP

\begin{tabular}{|c|c|c|c|}
\hline Liquor-to-wood Ratio & Active Alkali $(\%)$ & Sulfidity $(\%)$ & Cooking Time $(\mathrm{h})$ \\
\hline $5: 1$ & 20,25, or 30 & 30 & 2 or 3 \\
\hline $4: 1$ & 20,25, or 30 & 30 & 2 or 3 \\
\hline
\end{tabular}

After preparing the PB-UKPs, their total yield was calculated by measuring their total dry weight. The pulps were fractionated using a Somerville screen (Daeil Machinery Co., Ltd., Daejeon, Republic of Korea) that was equipped with a slot-type screen to remove flakes larger than $40 \mathrm{~mm}$ and wider than $0.15 \mathrm{~mm}$. The fractionated pulp fibers were washed, and the screened yield was calculated by measuring the weight of fractionated pulps. These fractionated pulps were used in subsequent experiments. To analyze the shape of pulp fibers after kraft pulping before fractionation, images were captured using a scanning electron microscope (SEM, JSM-5600LV; JEOL Ltd., Tokyo, Japan) at an accelerating voltage of $15 \mathrm{kV}$. Samples are coated with a thin layer of gold for $120 \mathrm{~s}$.

\section{Bleaching of $P B-U K P$ and measurement of $P B-B K P$ properties}

To make the PB-BKP, three-stage bleaching was performed as per the conditions shown in Table 2 . The $\mathrm{pH}$ was adjusted to 3 by adding acetic acid to sodium chlorite such that the amount of chlorine dioxide corresponding to each of the D-stage conditions was produced. The E-stage $\mathrm{pH}$ was adjusted to 11 . The bleaching chemicals and distilled water were added to the pulp-containing polyethylene bag such that the final consistency could be controlled to $10 \%$. The reaction was allowed to take place in a water bath at $80{ }^{\circ} \mathrm{C}$ for a total of $60 \mathrm{~min}$. During this time, the plastic bag was massaged thoroughly at $15 \mathrm{~min}$ intervals to ensure the chemical solution was evenly mixed. After each reaction stage, the pulp slurry was sufficiently washed with distilled water to remove remaining chemicals to ensure that they did not influence the next bleaching stage. 
Table 2. Bleaching Conditions Used to Prepare PB-BKP

\begin{tabular}{|c|c|c|c|c|}
\hline \multirow{2}{*}{ Condition } & $\mathrm{D}_{0}$ & $\mathrm{E}$ & $\mathrm{D}_{1}$ & \multirow{2}{*}{ Total $^{2} \mathrm{ClO}_{2}(\%)$} \\
\cline { 2 - 4 } & $\mathrm{ClO}_{2}(\%)$ & $\mathrm{NaOH}(\%)$ & $\mathrm{ClO}_{2}(\%)$ & \\
\hline 1 & 3.0 & 1.5 & 1.0 & 4.0 \\
\hline 2 & 4.0 & 2.0 & 1.0 & 5.0 \\
\hline 3 & 3.0 & 1.5 & 3.5 & 6.5 \\
\hline 4 & 4.0 & 2.0 & 2.5 & 6.5 \\
\hline 5 & 5.0 & 2.5 & 1.5 & 6.5 \\
\hline
\end{tabular}

To evaluate the dependence of the brightness of PB-BKP on the bleaching conditions, pads were prepared with a grammage of $100 \mathrm{~g} / \mathrm{m}^{2}$ using vacuum filtration. The ISO brightness was measured under light-source $\mathrm{C}$ using a spectrophotometer (L\&W Elrepho; L\&W, Stockholm, Sweden) according to the following standard TAPPI T452 om-08 (2008). To determine the damage to cellulose as a result of bleaching treatments of PB-BKP, the viscosity was measured using cupriethylene diamine (CED) according to the following standard TAPPI T230 om-08 (2008). The degree of polymerization (DP) of PB-BKP was calculated using Eq. 1 (Iribarne and Schroeder 1997):

$$
\begin{aligned}
& \mathrm{DP}=961.38 \times \log n_{\mathrm{T}}-245.3 \\
& n_{\mathrm{T}}=\text { The TAPPI T230 viscosity }
\end{aligned}
$$

\section{Measurement of the characteristics of $P B-U K P$ and $P B-B K P$}

To analyze the dewatering property of the PB-UKP and PB-BKP, the initial freeness was measured using a Canadian Standard Freeness (CSF) tester according to the standard TAPPI T227 om-09 (2009). A fiber analyzer (FQA-360; OpTest Equipment Inc., Hawkesbury, Canada) was used to measure the length and width of the fibers. Lastly, to analyze the shape of pulp fibers after kraft pulping before fractionation, images were obtained at $40 \times, 100 \times$, and $200 \times$ using an optical microscope (BX51; Olympus, Tokyo, Japan).

\section{RESULTS AND DISCUSSION}

\section{Chemical Composition Analysis of Persimmon Byproducts and Yield Measurement of PB-UKP}

Table 3 shows the chemical composition of the persimmon byproduct measured in this study and that of various fibrous resources reported in previous studies (Senthil Kumar et al. 2010; Gonźalez et al. 2011; Mohamed and Hassabo 2015; Phinichka and Kaenthong 2018; Tang et al. 2019). Both the cellulose and hemicellulose contents of the persimmon byproduct were similar to those of pine and birch. Moreover, this value was similar or higher than those of other non-woody resources. The concentration of other components in persimmon byproduct was similar to those of the components in pine and birch. Therefore, the persimmon byproducts have holocellulose contents sufficient for chemical pulping. 
Table 3. Chemical Compositions of Various Resources

\begin{tabular}{|c|c|c|c|c|c|c|}
\hline $\begin{array}{c}\text { Chemical } \\
\text { Composition } \\
(\%)\end{array}$ & $\begin{array}{l}\text { Persimmon } \\
\text { Byproduct }^{\mathrm{a}}\end{array}$ & Pine $e^{b}$ & Birch $^{b}$ & Bagasse $^{c}$ & Bamboo $^{d}$ & Rice husk ${ }^{e}$ \\
\hline Cellulose & 40.3 & 40 & 41 & 41.42 & 31.88 & 31.12 \\
\hline Hemicellulose & 31.2 & 28.5 & 32.4 & 28.11 & 22.92 & 22.48 \\
\hline Lignin & 22.0 & 27.7 & 22.0 & 19.03 & 28.49 & 22.34 \\
\hline Extractives & 3.4 & \multirow{2}{*}{$<5$} & \multirow{2}{*}{$<5$} & 4.16 & - & 2.33 \\
\hline Ash & 2.8 & & & - & - & 13.87 \\
\hline
\end{tabular}

a measured in laboratory and ${ }^{b-e}$ cited from the literature (b: Mohamed et al. 2015, c:

Phinichka et al. 2018, d: Tang et al. 2019, e: Senthil Kumar et al. 2010)

Figures 2 and 3 show the total yield and screened yield of PB-UKPs at liquorto-wood ratios of 5:1 and 4:1, respectively. Total yield and screened yield ranged from $34-53 \%$ and $27-34 \%$, respectively. Screened yield is overall lower than common hardwood pulp and other studies (López et al. 2000; González et al. 2013; Robisnéa et al. 2018) because persimmon byproduct chips used in this study were less than $5 \mathrm{~cm}$ diameter and the bark was not removed (Macleod 2006).

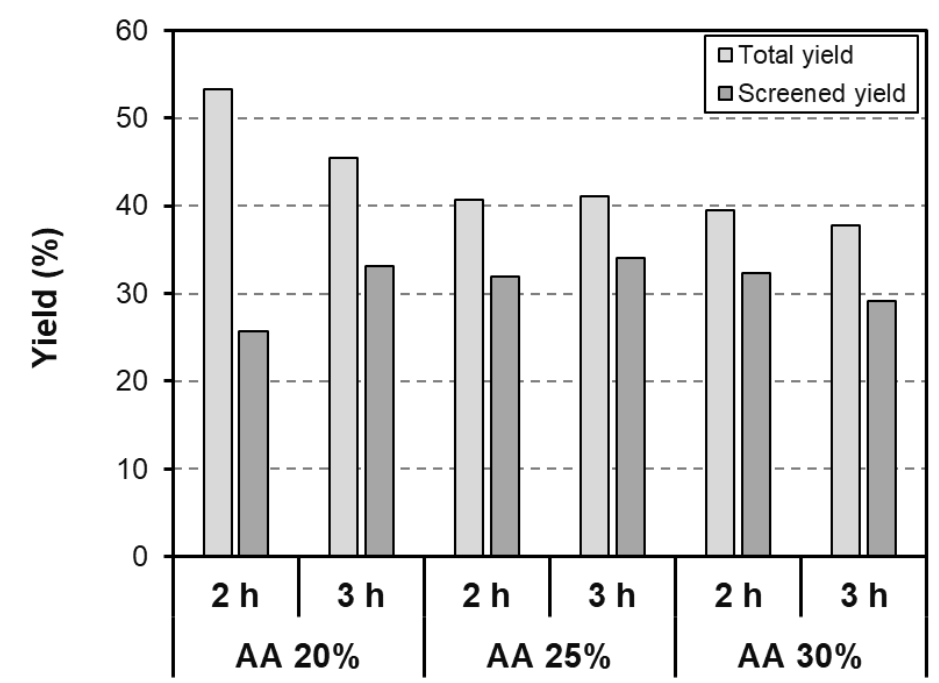

Fig. 2. Total yield and screened yield of persimmon byproduct kraft pulps at liquor-to-wood ratio of $5: 1$ (sulfidity: $30 \%$ )

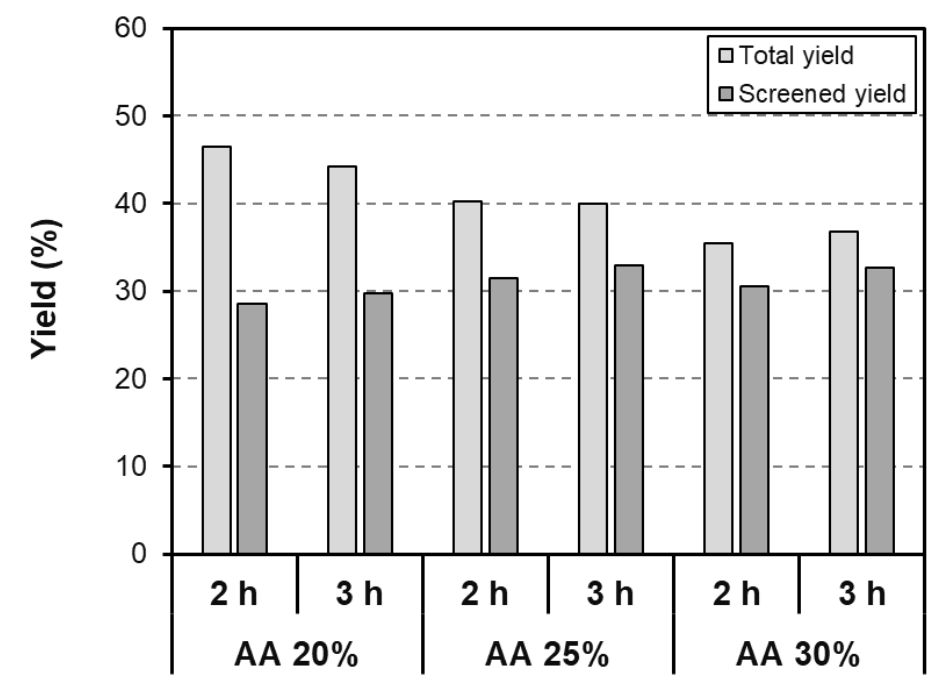

Fig. 3. Total yield and screened yield of persimmon byproduct kraft pulps at liquor-to-wood ratio of $4: 1$ (sulfidity: $30 \%$ ) 
With an increase in the AA of white liquor and cooking time, the total yield decreased because extractives and lignin were more easily removed as the pulping conditions became stronger. Moreover, the screened yield of PB-UKPs increased as the total yield decreased and the pulping conditions became stronger. This result was attributed to the gradual increase in the fiber content that passed through the screen because of effective fiber separation. However, the total yield decreased to $<40 \%$ when the AA of the liquor was $>30 \%$. According to the results of chemical composition analysis, the cellulose content of persimmon byproducts was $>40 \%$. Moreover, the total yield of PB-UKP decreased to $<40 \%$ because the cellulose was partially extracted with extractives, lignin, and hemicellulose under strong pulping conditions. Therefore, the AA of liquor should be controlled to $<30 \%$ to achieve a high pulp yield. Note that the liquor-to-wood ratio of 5:1 showed a higher total yield and a higher screened yield than that of 4:1. The high liquor-to-wood ratio diluted the concentration of white liquor in the digester; thus, the diluted white liquor appeared to reduce the degree of kraft pulping (Zhao et al. 2011). Figures 4 and 5 show SEM images of the fibers in persimmon byproduct kraft pulps prepared under a liquor-to-wood ratio of 5:1, an AA of $25 \%$, a sulfidity of $30 \%$, and a cooking time of $3 \mathrm{~h}$. When the persimmon byproduct kraft pulp was produced under the pulping conditions that led to the highest yield, fiber bundles were not observed and the individual fibers could be efficiently separated. Therefore, the optimal pulping conditions for the highest screened yield of persimmon byproduct kraft pulp can be summarized as follows: a liquor-to-wood ratio of 5:1, an AA of $25 \%$, a sulfidity of $30 \%$, and a cooking time of $3 \mathrm{~h}$.

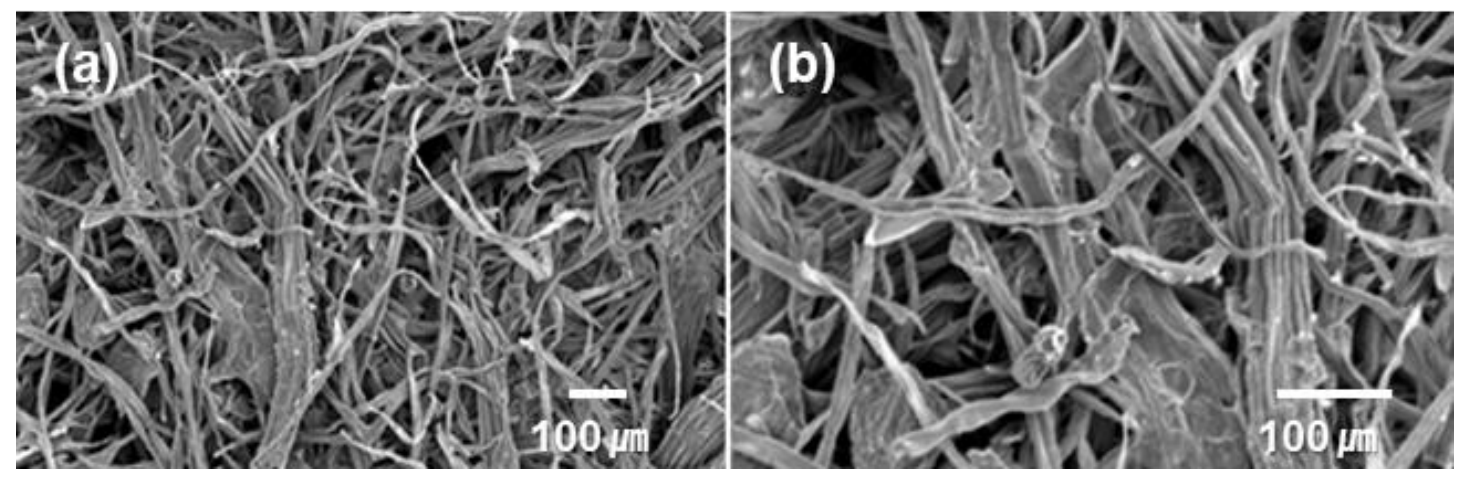

Fig. 4. SEM images of persimmon byproduct kraft pulp fibers prepared under a liquor-to-wood ratio of $5: 1$, an $A A$ of $20 \%$, a sulfidity of $30 \%$, and a cooking time of $2 \mathrm{~h}$ : (a) $100 \times$ magnification and (b) 200x magnification

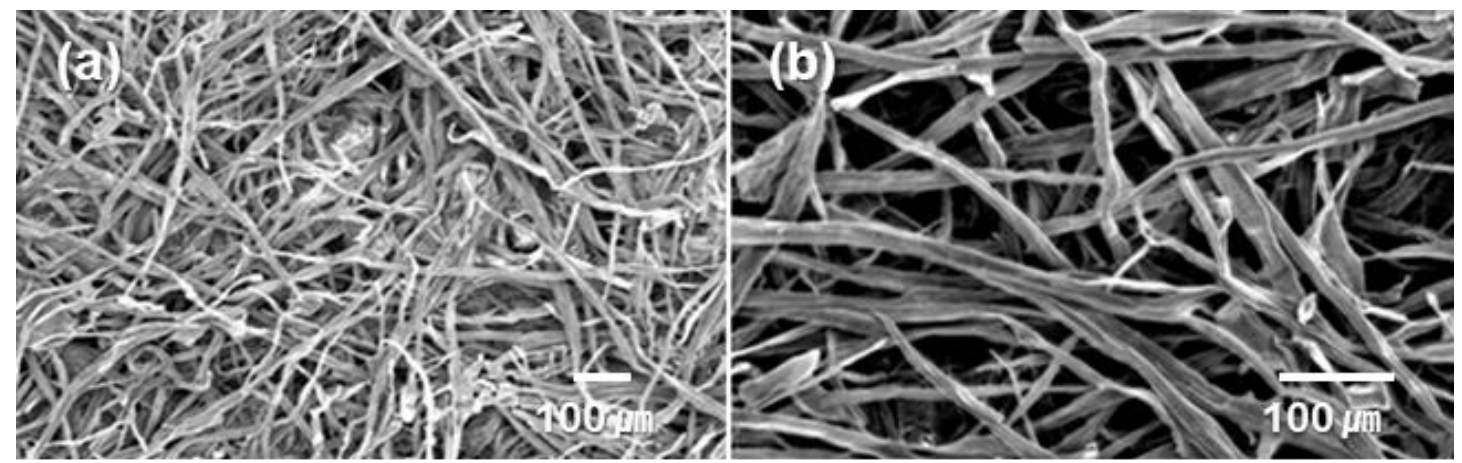

Fig. 5. SEM images of persimmon byproduct kraft pulp fibers prepared under a liquor-to-wood ratio of $5: 1$, an AA of $25 \%$, a sulfidity of $30 \%$, and a cooking time of $3 \mathrm{~h}$ : (a) $100 \times$ magnification and (b) 200x magnification 


\section{Evaluation of Bleaching Properties of PB-UKP}

Three-stage bleaching was performed under various conditions to prepare PBBKPs from PB-UKP made under optimal pulping conditions. Figure 6 shows the ISO brightness of PB-BKPs after the $\mathrm{D}_{0}$ stage. The ISO brightness was proportional to the concentration of chlorine dioxide because it is a strong oxidant that selectively destroys the lignin and the chromophoric groups of pulp without substantially affecting its cellulose or hemicellulose (Smook 2004; Kaur et al. 2018). After one stage of chlorine dioxide treatment, the ISO brightness increased to a maximum of $44 \%$. Figure 7 shows the final ISO brightness of the PB-BKPs after three-stage bleaching. The ISO brightness of the pulp increased with the total chlorine dioxide dosage. The final ISO brightness was $>73 \%$ when the total chlorine dioxide dosage was $6.5 \%$. Moreover, when comparing conditions 2 and 4, condition 4 resulted in a higher ISO brightness than condition 2. Note that conditions 2 and 4 had the same chlorine dioxide and sodium hydroxide dosages in the $\mathrm{D}_{0}$ and $\mathrm{E}$ stages, but condition 4 had a higher chlorine dioxide input in the $\mathrm{D}_{1}$ stage. Therefore, the final stage of chlorine dioxide dosage is considered to be the most important factor in attaining high ISO brightness (Parthasarathy and Colodette 2010).

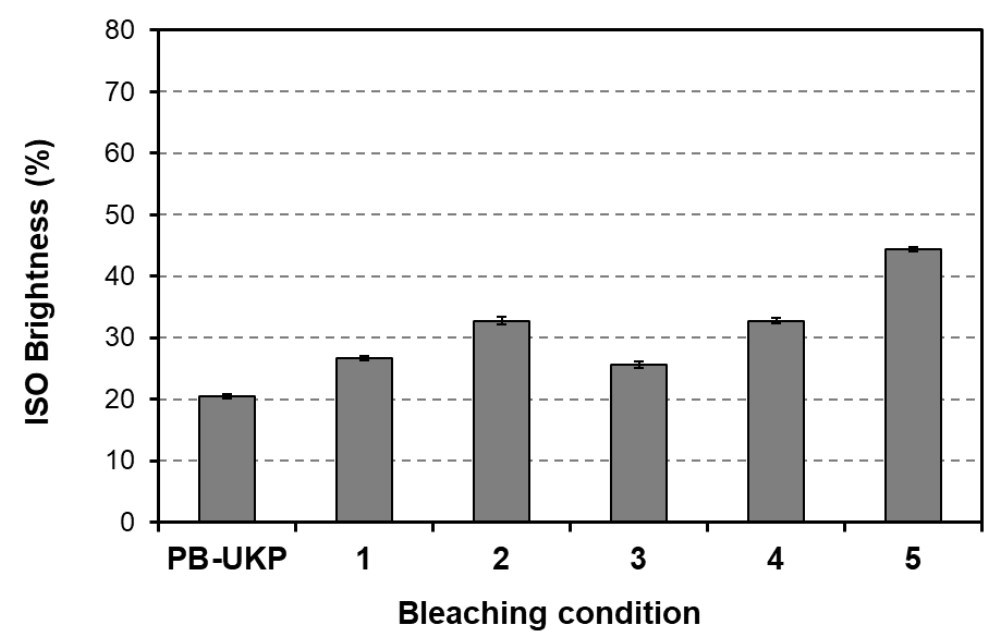

Fig. 6. ISO brightness of PB-BKP after stage $D_{0}$

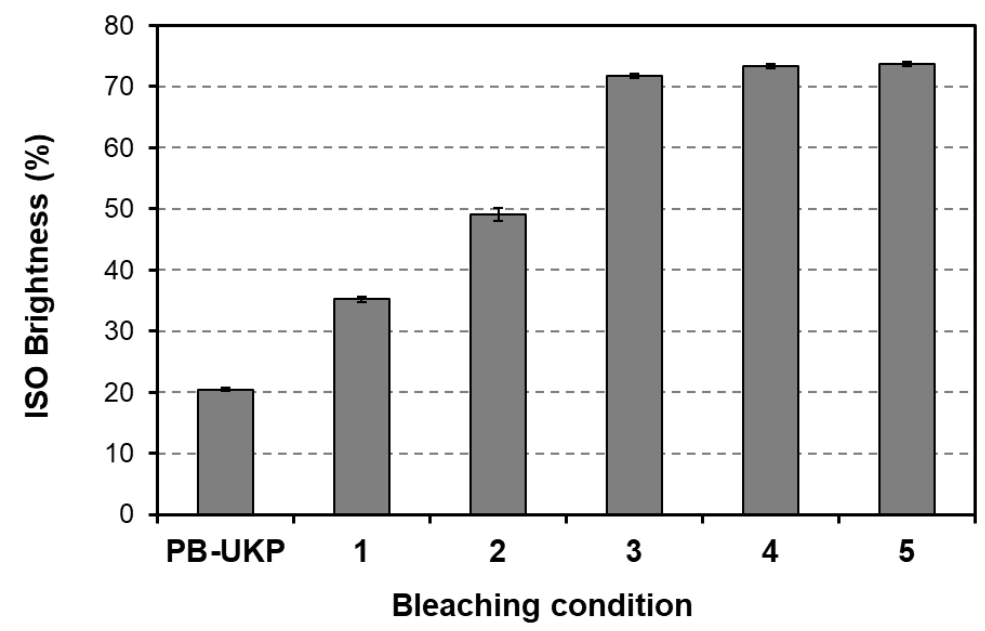

Fig. 7. ISO brightness of PB-BKP after three stages 
Table 4 shows the effect of bleaching conditions on the CED viscosity and the $\mathrm{DP}$ of the PB-BKP. Both the viscosity and DP did not show a significant change from condition 1 to condition 3 . However, as the chlorine dioxide concentration in the $\mathrm{D}_{0}$ stage increased, the viscosity and DP of the PB-BKP decreased. The chlorine-based reagent, which is a strong oxidizing agent, and the high reaction temperature are blamed for the degradation of cellulose and lignin (Cheng et al. 2013), and this is why the pulp viscosity and DP of PB-BKP decreased rapidly after condition 5. Therefore, condition 3 is considered to be the optimal condition, and the characteristics of PB-BKP under condition 3 were characterized further.

Table 4. Final CED Viscosity and DP of PB-BKP Depending on Bleaching Condition

\begin{tabular}{|c|c|c|c|c|c|}
\hline Bleaching Condition & 1 & 2 & 3 & 4 & 5 \\
\hline Pulp viscosity (cPs) & 17.0 & 15.5 & 16.9 & 13.8 & 8.3 \\
\hline DP & 874.3 & 863.6 & 879.6 & 805.5 & 648.5 \\
\hline
\end{tabular}

\section{Evaluation of the Characteristics of PB-UKP and PB-BKP}

Figure 8 shows the initial freeness of PB-UKP, PB-BKP, and commercial BKPs obtained from Moorim Paper. As PB-UKP was bleached, the initial freeness of PBBKP decreased approximately $15 \mathrm{~mL}$ CSF; however, the decrease was unremarkable. Figures 9 and 10 show the average fiber length and average fiber width of pulps. The average fiber length of SwBKP was the highest, while HwBKP, PB-UKP, and PB-BKP showed similar average fiber lengths. No noticeable difference was observed in the average fiber length between PB-UKP and PB-BKP. However, the average fiber width of SwBKP was the highest, whereas that of HwBKP was the lowest. Furthermore, no remarkable difference was observed between PB-UKP and PB-BKP. In addition, the analysis of fiber morphology, as shown in Figs. 11, 12, and 13 showed that PB-BKP was similar to HwBKP. These results suggest that PB-BKP had characteristics similar to those of commercial HwBKP; however, PB-BKP showed 13\% lower ISO brightness than HwBKP, as shown in Fig. 14. Therefore, PB-BKP prepared under optimal pulping and bleaching conditions exhibited physical characteristics similar to those of commercial HwBKP but had a relatively low ISO brightness.

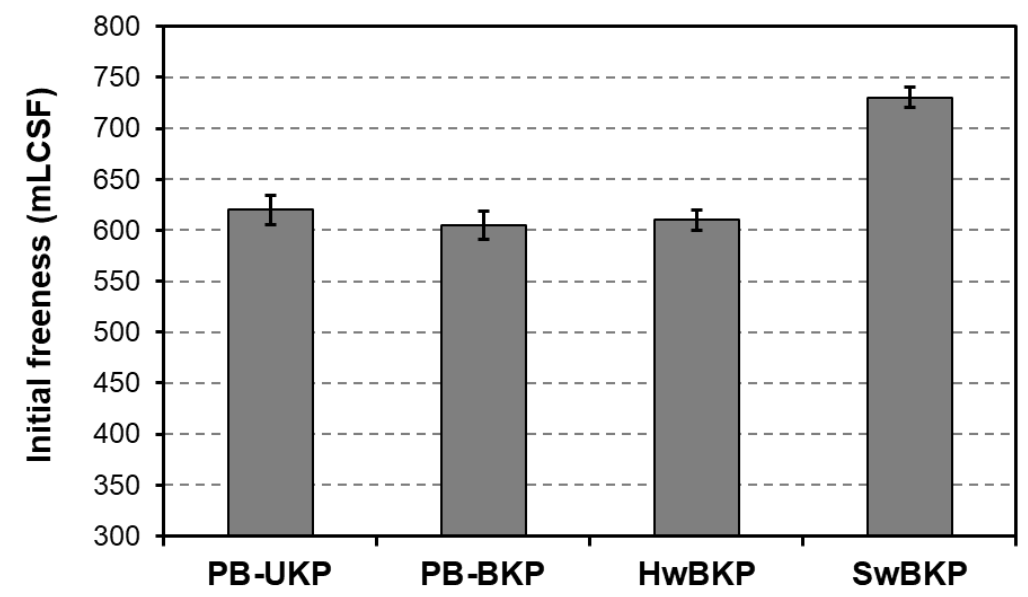

Fig. 8. Initial freeness of PB-UKP, PB-BKP, and commercial BKPs 


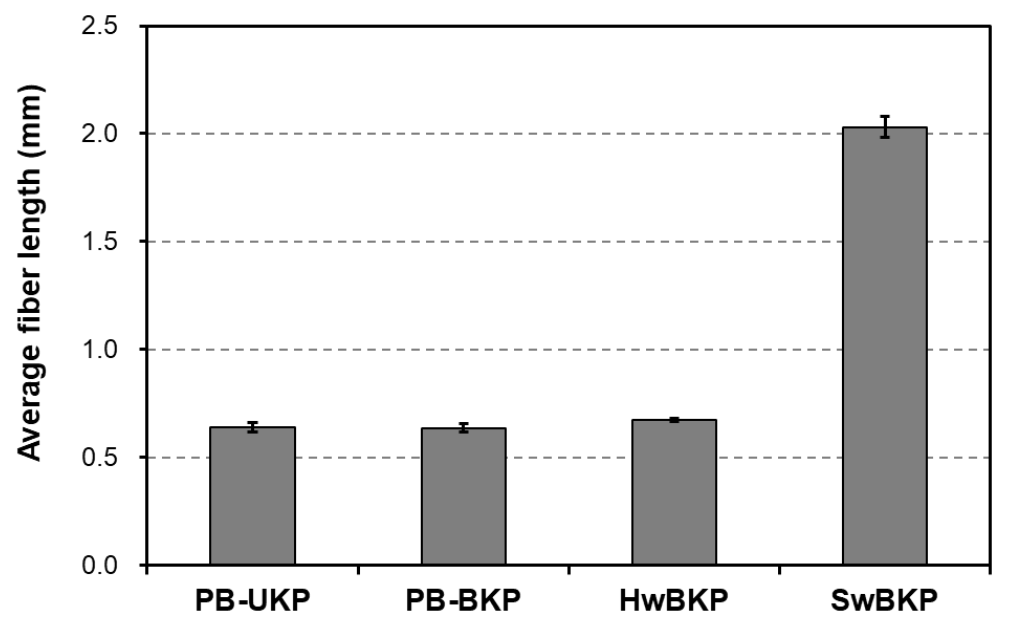

Fig. 9. Average fiber length of PB-UKP, PB-BKP, and commercial BKPs

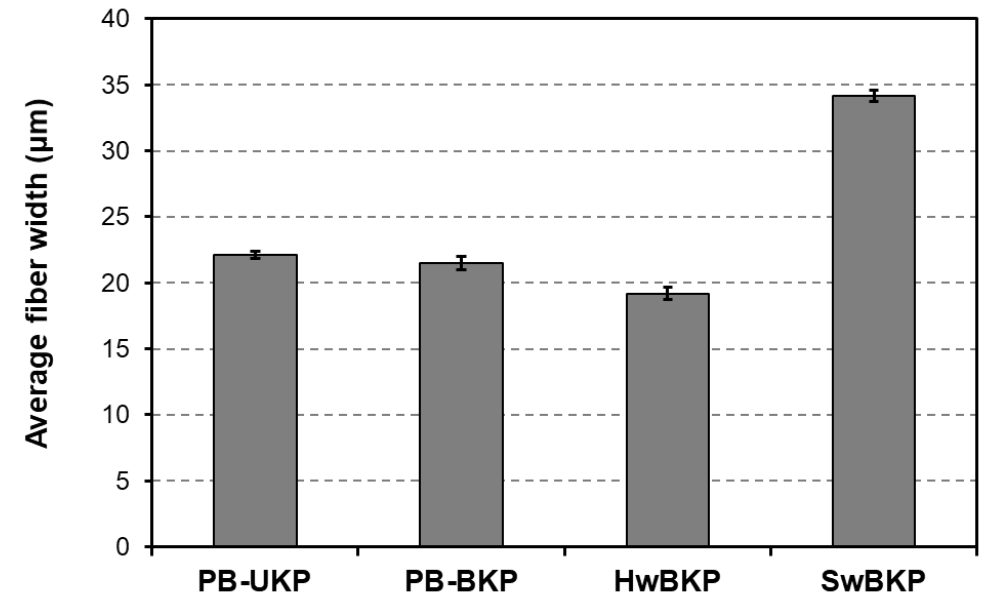

Fig. 10. Average fiber width of PB-UKP, PB-BKP, and commercial BKPs

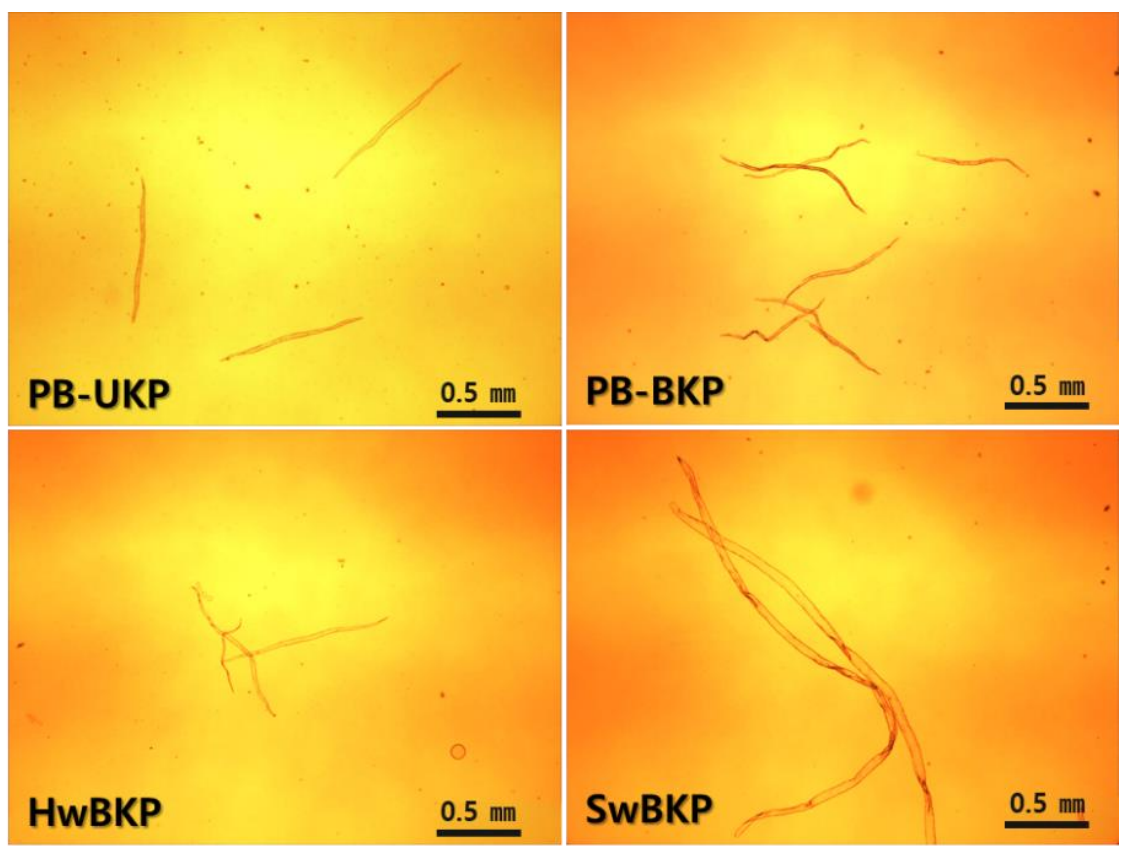

Fig. 11. Microscopic images of PB-UKP, PB-BKP, and commercial BKPs: $40 \times$ magnification 


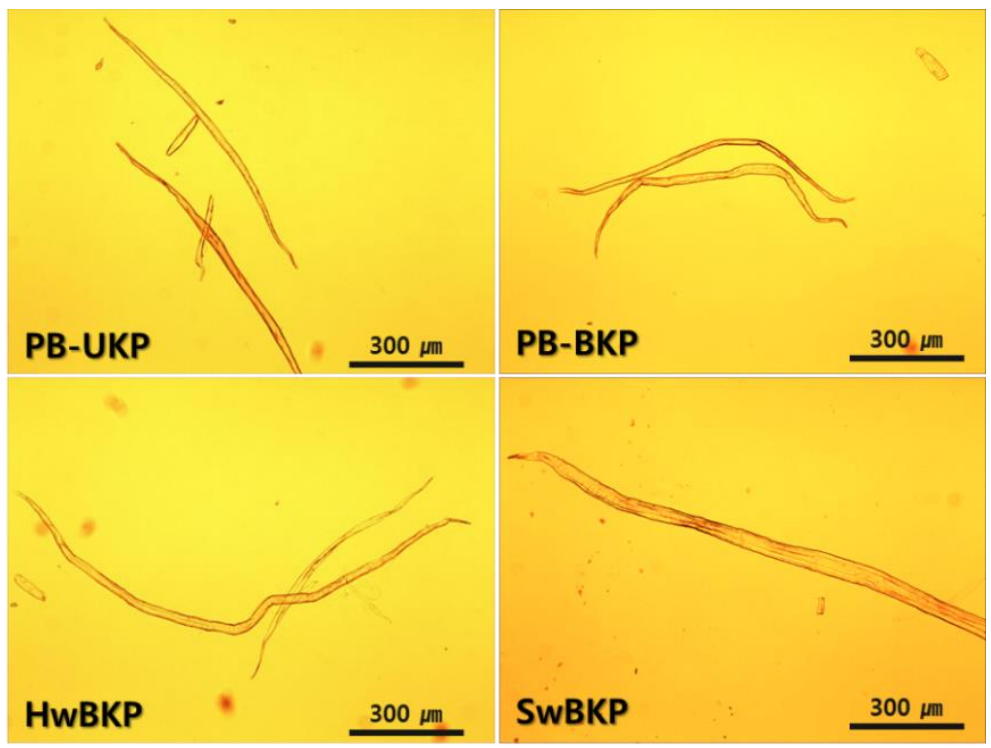

Fig. 12. Microscopic images of PB-UKP, PB-BKP, and commercial BKPs: $100 \times$ magnification

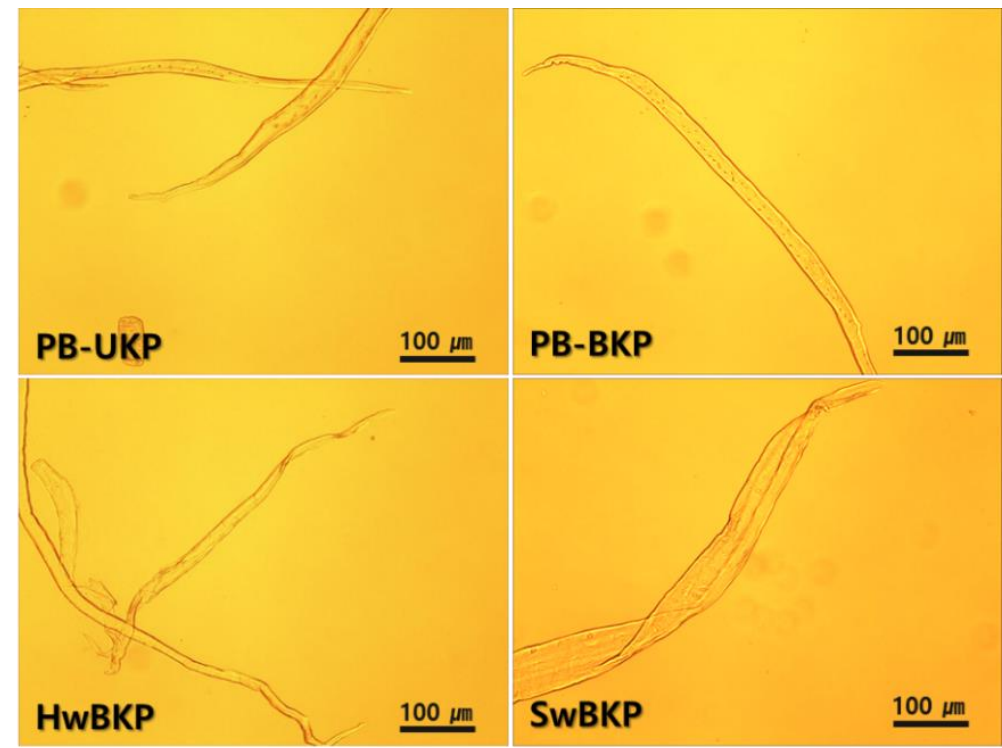

Fig. 13. Microscopic images of PB-UKP, PB-BKP, and commercial BKPs: $200 \times$ magnification

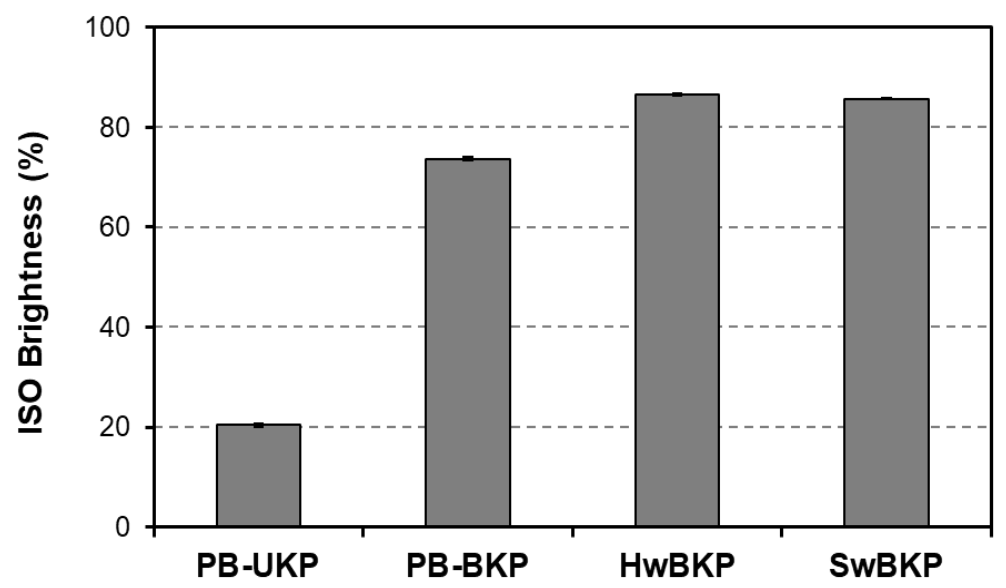

Fig. 14. ISO brightness of PB-UKP, PB-BKP, and commercial BKPs 


\section{CONCLUSIONS}

1. The chemical composition of persimmon byproducts was similar to those of pine and birch and was suitable for producing chemical pulps.

2. The optimal pulping conditions for the highest screened yield of persimmon byproduct unbleached kraft pulp (PB-UKP) can be summarized as a liquid ratio of $5: 1$, an active alkali (AA) of $25 \%$, a sulfidity of $30 \%$, and a cooking time of $3 \mathrm{~h}$. However, it was thought that the final screened yield of PB-UKP made under optimal pulping conditions was lower than that of common kraft pulps made from softwoods or hardwoods.

3. The optimal bleaching conditions of PB-UKP for maximum ISO brightness within the range that does not damage the pulp fibers can be summarized as $\mathrm{D}_{0}(3.0 \%$ $\left.\mathrm{ClO}_{2}\right)-\mathrm{E}(1.5 \% \mathrm{NaOH})-\mathrm{D}_{1}\left(3.5 \% \mathrm{ClO}_{2}\right)$.

4. Persimmon byproduct bleached kraft pulp prepared under optimal pulping and bleaching conditions had physical characteristics similar to those of commercial mixed HwBKP but had a relatively low ISO brightness. Therefore, as a raw material, persimmon byproduct can be used for manufacturing bleached kraft pulp.

\section{ACKNOWLEDGEMENTS}

This work was supported by the Korea Institute of Planning and Evaluation for Technology in Food, Agriculture and Forestry (IPET) through the Agri-Bio Industry Technology Development Program, funded by Ministry of Agriculture, Food and Rural Affairs (MAFRA) (118040-3).

\section{REFERENCES CITED}

Bhardwaj, N. K., Goyal, S. K., Gupta, A., and Ray, A. K. (2005). "Soda and sodaanthraquinone pulping of rice straw," Appita Journal 58(3), 180-185.

Cheng, M., Hui, L. F., Liu, Z. K., and Tang, X. (2013). "Evaluation of hemp root bast as a new material for papermaking," BioResources 9(1), 132-142. DOI: 10.15376/biores.9.1.132-142

El-Sakhawy, M., Lönnberg, B., Fahmy, Y., and Ibrahim, A. A. (1996). “Organosolv pulping. 3. Ethanol pulping of wheat straw," Cellulose Chemistry and Technology 30(1-2), 161-174.

Eom, T. J. (2014). "Asia pulp and paper industry trend," World Agriculture 164, Korea Rural Economic Institute, Naju, Republic of Korea, pp. 210-212.

Fahmy, Y., Fahmy, T. Y. A., Mobarak, F., El-Sakhawy, M., and Fadl, M. H. (2017).

"Agricultural residues (wastes) for manufacture of paper, board, and miscellaneous products: Background overview and future prospects," International Journal of ChemTech Research 10(2), 425-448. DOI: 10.5281/zenodo.546735

Fillat, Ú., Wicklein, B., Martín-Sampedro, R., Ibarra, D., Ruiz-hitzky, E., Valencia, C., Sarrión, A., Castro, E., and Eugenio, M. E. (2018). "Assessing cellulose nanofiber production from olive tree pruning residue," Carbohydrate Polymers 179, 252-261. DOI: 10.1016/j.carbpol.2017.09.072

González, Z., Rosal, A., Requejo, A., and Rodríguez, A. (2011). "Production of pulp 
and energy using orange tree prunings," Bioresource Technology 102(19), 93309334. DOI: 10.1016/j.biotech.2011.07.088

González, Z., Rodrígues, A., Vargas, F., and Jiménez, L. (2013). "Influence of the operational variables on the pulping and beating of the orange tree pruning," Industrial Crops and Products 49, 785-789. DOI:10.1016/j.indcrop.2013.06.014

Iribarne, J., and Schroeder, L. R. (1997). "High-pressure oxygen delignification of kraft pulps. Part 1. Kinetics," TAPPI Journal 80(10), 241-250.

Iriondo-DeHond, M., Miguel, E., and Castillo, M. D. (2019). "Byproducts as a source of novel ingredients in dairy foods," Encyclopedia of Food Security and Sustainability 1, 316-322. DOI: 10.1016/B978-0-08-100596-5.22137-9

Jeong, J. S. (2016). 2016 Wood Supply Performance Reports, Department of Forest Materials, Korea Forest Service, Daejeon, Republic of Korea.

Jesus, M. S., Romaní, A., Genisheva, Z., Teixeira, J. A., and Domingues, L. (2017). "Integral valorization of vine pruning residue by sequential autohydrolysis stages," Journal of Cleaner Production 168, 74-86. DOI: 10.1016/j.jclepro.2017.08.230

Kang, S. U. (2017). 2017 Crop Production Survey Report (No. 11-1240000-00051210), Statistics Korea, Daejeon, Republic of Korea.

Kaur, D., Bhardwaj, N. K., and Lohchab, R. K. (2017). "Prospects of rice straw as a raw material for paper making," Waste Management 60, 127-139. DOI: 10.1016/j.wasman.2016.08.001

Kaur, D., Bhardwaj, N. K., and Lohchab, R. K. (2018). "A study on pulping of rice straw and impact of incorporation of chlorine dioxide during bleaching on pulp properties and effluents characteristics," Journal of Cleaner Production 170(1), 174-182. DOI: 10.1016/j.jclepro.2017.09.111

Kim, B. S., Lee, C. S., Hwang, Y. J., Goo, S. H., Kim, J. O., Shin, S. R., Lee, J. H., and Park, E. J. (2014). A Report of Development of Biomass Energy Promotion Strategy (No. 11-1543000-000685-01), Ministry of Agriculture Food and Rural Affairs in the Republic of Korea, Sejong, Republic of Korea.

KS M 7035 (2018). "Testing method for alcohol-benzene soluble matters in raw material for pulp," Korean Agency for Technology and Standards, Eumseong-gun, Chungcheongbuk-do, Republic of Korea.

Lee, J. Y., Lim, G. B., Kim, S. Y., Park, J. H., Kim, C. H., Hur, Y. J., Kim, Y. H., Kim, Y. O., and Lee, S. R. (2014). "Evaluation of the physical properties of kraft pulps made from major agricultural byproducts," Journal of Korea TAPPI 46(3), 50-57. DOI: 10.7584/ktappi.2014.46.3.050

López, F., Ariza, J., Pérez, I., and Jiménez, L. (2000). "Comparative study of paper sheets from olive tree wood pulp obtained by soda, sulphite of kraft pulping," Bioresource Technology 71(1), 83-86. DOI:10.1016/S0960-8524(99)00044-9

Macleod, M. (2006). "The top ten factors in kraft pulp yield," Paper and Timber 89(4), 1-7.

Mohamed, A., and Hassabo, A. (2015). "Flame retardant of cellulosic materials and their composites," in: Flame retardants, Visakh, P. M., and Arao, Y (eds.), Springer International Publishing, New York, United States of America. pp. 252.

Parthasarathy, V. R., and Colodette, J. (2010). "Influence of final bleaching stage on ECF brightness development, refineability and pulp properties," Scientia Forestalis/Forest Sciences 38(86), 135-146.

Phinichka, N., and Kaenthong, S. (2018). "Regenerated cellulose from high alpha cellulose pulp of steam-exploded sugarcane bagasse," Journal of Materials Research and Technology 7(1), 55-65. DOI: 10.1016/j.jmrt.2017.04.003

Robisnéa, A. R., Jorge, L. C., and Sílvio, V. J. (2018). "Effect of residual effective 
alkali on eucalyptus kraft pulp yield and chemistry," CERNE 24(4), 408-419. DOI:10.1590/01047760201824042593

Senthil Kumar, P., Ramakrishnan, K., Selvaraj Dinesh, K., and Sivanesan, S. (2010). "Thermodynamic and kinetic studies of cadmium adsorption from aqueous solution on to rice husk," Brazilian Journal of Chemical Engineering 27(2), 347355. DOI:10.1590/S0104-66322010000200013

Smook, G. A. (2004). "Bleaching," in: Handbook for Pulp and Paper Technologists, J. M. Park, B. M. Jo, J. M. Won, and C. H. Kim (eds.), Seoil Press, Suwon, Republic of Korea, pp. 199-211.

Tang, T., Chen, X., Zhang, Bo., Liu, Xi., and Fei, B. (2019). "Research on the physico-mechanical properties of moso bamboo with thermal treatment in tung oil and its influencing factors," Materials 12(4), 599. DOI: 10.3390/ma12040599

TAPPI T211 om-07 (2007). "Ash in wood, pulp, paper and paperboard: Combustion at $525^{\circ} \mathrm{C}$," TAPPI Press, Atlanta, GA, USA.

TAPPI T227 om-09 (2009). "Freeness of pulp (Canadian standard method)," TAPPI Press, Atlanta, GA, USA.

TAPPI T230 om-08 (2008). "Viscosity of pulp (capillary viscometer method)," TAPPI Press, Atlanta, GA, USA.

TAPPI T452 om-08 (2008). "Brightness of pulp, paper, and paperboard (directional reflectance at $457 \mathrm{~nm}$ )," TAPPI Press, Atlanta, GA, USA.

Wi, K. W., Lee, H. S., Lim, S. M., Song, H., Hussin, M. W., and Ismail, M. A. (2018). "Use of an agricultural by-product, nano sized palm oil fuel ash as a supplementary cementitious material," Construction and Building Materials 183, 139-149. DOI: 10.1016/j.conbuildmat.2018.06.156

Wise, L. E., Murphy, M., and D'adieco, A. A. (1946). "Chlorite holocellulose, its fractionation and bearing on summative wood analysis and on studies on the hemicelluloses," Paper Trade Journal 122(2), 35-43.

Zhao, X., Heide, E., Zhang, T., and Liu, D. (2011). "Single-stage pulping of sugarcane bagasse with peracetic acid," Journal of Wood Chemistry and Technology 31(1), 1-25. DOI: 10.1080/02773811003637494

Article submitted: September 11, 2019; Peer review completed: November 17, 2019; Revised version received: November 24, 2019; Accepted: November 25, 2019; Published: December 2, 2019.

DOI: $10.15376 /$ biores.15.1.492-504 